\title{
Application of Fuzzy Data Envelopment Analysis in Decision Making
}

\author{
Akhilesh Kumar, PhD \\ Magadh University, Bodhgaya
}

\begin{abstract}
In this research work, Data Envelopment Analysis (DEA) is broadly connected in assessing the productivity of banks since it may be a strategy able of assessing the proficiency of choice making units in utilizing different inputs to deliver numerous yields. Be that as it may, a few yields of banks, in truth, have Fuzzy property, whereas ordinary DEA approach can as it were evaluate productivity with a fresh esteem and is incapable to assess loose information. Hypothetically, the Fuzzy Data Envelopment Analysis (FDEA) approach can assess banks' productivity more reasonable and exact since it can take the fuzzy property of inputs and/or yields into thought. The comes about appear that the FDEA approach could not as it were successfully differentiate instability, but too may have a better capability to segregate banks' effectiveness than the ordinary DEA method.
\end{abstract}

\section{Keywords}

Data Envelopment Analysis, Fuzzy Data Envelopment Analysis, -cut, inaccurate data.

\section{INTRODUCTION}

Data Envelopment analysis (DEA) may be a strategy able of assessing the productivity of decision making units (DMUs) in utilizing numerous inputs to deliver numerous yields; thus, it is broadly connected in assessing the productivity of banks $[1,2,3,4,5,6]$. Be that as it may, the routine DEA demonstrate can as it were evaluate proficiency with a fresh esteem and is incapable to assess uncertain information [7-8]. In this way, the a few other researcher has been proposed a bound together approach to treating blends including correct as well as loose information, whereas a few of the information may be know as it were inside indicated bounds, the other information may be known as it were in terms of ordinal relations [9]. In spite of the fact that the upgraded ponder given loose information utilizing the DEA approach, it did not bargain with information indicated in bounded shapes. The yields of banks, counting advance wage and venture pay, in reality, have fluffy characteristics: for illustration, credit allowing could be a hazardous yield since of the ex stake hazard for advances to in the long run ended up non-performing credits [10]. It is troublesome to precisely degree how numerous issue advances might gotten to be ordinary credits and how numerous typical advances might gotten to be issue advances. As for speculation, the investment pay of a bank, which isn't a steady number, changes every day on account of the advertise esteem of the speculation target changes day by day. To assess banks' proficiency more practically and precisely, this think about utilizes the fluffy DEA show with information indicated in bounded shapes to degree the effectiveness of banks.

Budgetary establishing in all nations are imperative parts of the chain within the money related frameworks. The quality of the monetary organizing decides the level of improvement of a country's economy. A solid budgetary institution depends on its resource quality, capacity, resource stream, capital satisfactory proportion, and etc. Be that as it may, competition between budgetary organizing has as of late developed furious. Slow expanding NPLs indeed affect economy genuinely. Within the late 1980s, Japanese banks by and large needed an mindfulness of dangers [11].

By the early 1990s, when the "bubble economy" collapsed, a expansive scale of undertakings went bankrupt coming about within the insurgence of NPLs in a vexed budgetary framework. In 1988, more than 200 American commercial banks went bankrupt, the increment of terrible resources and declining back uncovered the managing an account industry to liquidity dangers and genuine money related emergency. In 1997-98, the Asian money related emergency caused all the nations included, South Korea, Thailand, Indonesia, Malaysia and so forward, to endure from extreme increments in late credits and a compounding budgetary condition [12].

The influenced nations shared common issues of over the top risk-taking, particularly after the conservative liberalization in Southeast Asia, primarily since these nations needed an fitting administration framework [13]. Subsequently, a tall Non Performing Loan (NPL) proportion has been a common issue of the worldwide money related industry and comes about within the predicament of banks' operations. The most reason of this ponder is to require the fluffy marvels of yields into thought in arrange to viably consolidate NPLs to degree banks' proficiency. After distributing the fuzzy set that started in 1965 , Zadeh connected a scientific strategy to specific the fuzzy situation in a genuine environment and after that fuzzy set approach was presented into building science, making a establishment for the fuzzy set hypothesis [14]. The hypothesis is broadly connected from pharmaceutical to designing to the commercial field. FDEA, combined fuzzy set hypothesis with DEA show, is more able of dealing with disadvantages of information than the conventional DEA approach and is able to discover the interval for the fuzzy number proficiency score indeed in case the proper proficiency score of the fuzzy number is inaccessible. Moreover, a conceivable interim for the productivity score can be determined given a diverse $\alpha$-cut, and the more noteworthy the esteem is, the more conceivable it is to see an exact productivity score of the fuzzy number. Kao and Liu connected $\alpha$-cut and the expansion rule which Zadeh [14] proposed to convert a FDEA demonstrate into a customary fresh DEA demonstrate [7]. The upper and lower bounds on the participation capacities of the proficiency score are determined beneath a particular $\alpha$ level. Saati and other analyst have been proposed a Fuzzy CCR demonstrate with asymmetrical triangular fuzzy [15]. Entani and other analyst have been proposed the interim effectiveness score from the idealistic and the critical perspectives and amplified the thought into interim information or DEA demonstrate with fuzz information [16].

This consider basically examines the impact on bank productivity with fluffy yields and embraces fluffy set hypothesis to illuminate issues. The FDEA may, in expansion 
to measuring fluffy information, be connected to set up the upper and lower bounds of the effectiveness score and get profitable data from the interims between the upper and the lower bounds beneath a particular level. The application of FDEA show can more practically speak to real-world issues than the customary DEA models [17-18].

\section{THE FUZZY DEA MODEL}

Assume that there are H DMU creating M output by utilizing $\mathrm{N}$ inputs. In FDEA, inputs and outputs are characterized by vulnerability and thus we utilize $\mathrm{x}_{\_}$jn and $\mathrm{y}_{-} \mathrm{jm}$ to stand for $\mathrm{n}$ inputs and $m$ outputs of DMU_j, separately. Accept that the $\mathrm{x} \_j n_{\text {inputs and }} \mathrm{y}_{\_} \mathrm{jm}$ outputs are around known and can be spoken to by enrollment capacities and of the fuzzy set, individually. Note that the fresh esteem can be spoken to by degenerated membership capacities in which there's as it were one esteem in their space. The FDA demonstrates can be composed as takes after:

$$
\begin{gathered}
E_{j}^{O}=\max \left(\sum_{m=1}^{M} u_{m} y_{m j}-u_{0}\right) / \sum_{n=1}^{N} v_{n} \ell_{n j} \\
\text { s.t. } \quad\left(\sum_{m=1}^{M} u_{m} \theta_{m h}-u_{0}\right) / \sum_{n=1}^{N} v_{n} \ell_{m h} \leq 1, \quad h=1, \ldots, H \\
u_{1}, \ldots, u_{M}, v_{1}, \ldots, v_{N} \geq \varepsilon>0, u_{0} \text { is free }
\end{gathered}
$$

where is a small non-Archimedean quantity. Kao and Liu (2000) proposed a way to transform the fuzzy DEA model to the traditional crisp DEA model by applying -cut approach. The -cut of and are defined as follows:

$$
\begin{aligned}
\left(x_{j n}\right)_{\alpha}= & \left\{x_{j n} \in S\left(\tilde{x}_{j n}\right) \mid \mu_{\tilde{x}_{j n}}\left(x_{j n}\right) \geq \alpha\right\}=\left[\left(x_{j n}\right)_{\alpha}^{L},\left(x_{j n}\right)_{\alpha}^{U}\right] \\
= & {\left[\min _{x_{j n}}\left\{x_{j n} \in S\left(\tilde{x}_{j n}\right) \mid \mu_{\tilde{x}_{j n}}\left(x_{j n}\right) \geq \alpha\right\},\right.} \\
& \left.\max _{x_{j n}}\left\{x_{j n} \in S\left(\tilde{x}_{j n}\right) \mid \mu_{\tilde{x}_{j n}}\left(x_{j n}\right) \geq \alpha\right\}\right]
\end{aligned}
$$

(2)

$$
\begin{aligned}
\left(y_{j m}\right)_{\alpha}= & \left\{y_{j m} \in S\left(f g_{j m}\right) \mid \mu_{f_{g_{m}}}\left(y_{j m}\right) \geq \alpha\right\}=\left[\left(y_{j m}\right)_{\alpha}^{L},\left(y_{j m}\right)_{\alpha}^{U}\right] \\
= & {\left[\min _{y_{j m}}\left\{y_{j m} \in S\left(f g_{j m}\right) \mid \mu_{f_{g_{m}}}\left(y_{j m}\right) \geq \alpha\right\},\right.} \\
& \left.\max _{y_{j m}}\left\{y_{j m} \in S\left(f g_{g m}\right) \mid \mu_{f g_{m}}\left(y_{j m}\right) \geq \alpha\right\}\right]
\end{aligned}
$$

(3)

According to Zadeh's extension principle [14], the membership function of efficiency evaluation for DMUj may be defined as follows:

$$
\mu_{E_{j}^{0}}(z)=\sup _{x, y} \min \left\{\mu_{f_{f_{j}}}\left(x_{j n}\right), \mu_{f_{f_{m}}}\left(y_{j m}\right), \forall j, m,\left.n\right|_{z}=E_{j}(x, y)\right\}
$$

where $E_{j}(x, y)$ is the efficiency score calculated by the conventional BCC model under a set of $\mathrm{x}$ and $\mathrm{y}$. In order to find the bounds of the intervals for $\tilde{E}_{j}(x, y)$ at each possibility level $\alpha$, Kao and Liu suggest a pair of mathematical programming, which is function of $\alpha$, as follows [7-8]:

$$
\begin{gathered}
\left(E_{j}\right)_{\alpha}^{L}=\max \quad\left(\sum_{m=1}^{M} u_{m}\left(y_{j m}\right)_{\alpha}^{L}-u_{0}\right) / \sum_{n=1}^{N} v_{n}\left(x_{j n}\right)_{\alpha}^{U} \\
\text { s.t } \quad\left(\sum_{m=1}^{M} u_{m}\left(y_{j m}\right)_{\alpha}^{L}-u_{0}\right) / \sum_{n=1}^{N} v_{n}\left(x_{j n}\right)_{\alpha}^{U} \leq 1 \\
\left(\sum_{m=1}^{M} u_{m}\left(y_{h m}\right)_{\alpha}^{U}-u_{0}\right) / \sum_{n=1}^{N} v_{n}\left(x_{h n}\right)_{\alpha}^{L} \leq 1, h=1, \ldots, H, h \neq j \\
u_{1}, \ldots, u_{M}, v_{1}, \ldots, v_{N} \geq \varepsilon>0, u_{0} \text { is free. (5) } \\
\left(E_{j}\right)_{\alpha}^{U}=\max \quad\left(\sum_{m=1}^{M} u_{m}\left(y_{j m}\right)_{\alpha}^{U}-u_{0}\right) / \sum_{n=1}^{N} v_{n}\left(x_{j n}\right)_{\alpha}^{L} \\
\text { s.t } \quad\left(\sum_{m=1}^{M} u_{m}\left(y_{j m}\right)_{\alpha}^{U}-u_{0}\right) / \sum_{n=1}^{N} v_{n}\left(x_{j n}\right)_{\alpha}^{L} \leq 1 \\
\quad\left(\sum_{m=1}^{M} u_{m}\left(y_{h m}\right)_{\alpha}^{L}-u_{0}\right) / \sum_{n=1}^{N} v_{n}\left(x_{m n}\right)_{\alpha}^{U} \leq 1, h=1, \ldots, H, h \neq j \\
u_{1}, \ldots, u_{M}, v_{1}, \ldots, v_{N} \geq \varepsilon>0, \quad u_{0} \text { is free. }
\end{gathered}
$$

Equation (5) implies that in arrange to discover the negligible relative productivity of the DMUj compared with others, the information ought to be connected from the least yield esteem of the DMUj and the most reduced input esteem of other DMUs as well as the most elevated input esteem of the DMUj and the most noteworthy yield esteem of other DMUs. Additionally, equation (6) shows that for the maximal relative productivity of the DMUj compared with others, the information ought to be connected from the most elevated yield esteem of the DMUj and the most noteworthy input esteem of other DMUs as well as the least input esteem of the DMUj and the least yield esteem of other DMUs. Moreover, show (5) and (6) are ordinary DEA models able of deciphering into linear programming (LP) to get the ideal weights.

A distinctive $\square$ esteem implies a distinctive range/interval and a level of vulnerability of the effectiveness score. The more noteworthy the $\square$ esteem is, the littler the range/interval of upper and lower bounds is and the lower the level of instability is. The esteem implies the largest extend that the effectiveness score will rise, and implies the productivity score that's most likely to be achieved.

FDEA may result in a fuzzy effectiveness score. Picking the finest DMU from various fuzzy productivity scores cannot be exclusively decided by the fuzzy effectiveness score. Hence, positioning fuzzy efficiency score gets to be the key to finding the finest DMU. There are numerous positioning strategies for fuzzy numbers [15], [19-22]. In any case, most of the positioning approaches require known enrollment capacities, which are troublesome to procure within the genuine world. This consider receives the approach, proposed by Chen and Klein, to rank the fluffy numbers as it were based on -cut [23].

Chen and Klein have been proposed the method for finding the index to rank [23]:

Where $c=\min _{i, j}\left\{\left(E_{j}\right)_{\alpha_{i}}^{L}\right\}$

and $d=\max _{i, j}\left\{\left(E_{j}\right)_{\alpha_{i}}^{U}\right\}$. 
The fuzzy DEA model of this study may be divided into four steps, as described below:

1. Calculate crisp type value into fuzzy type value known as fuzzy membership function.

2. Determine the upper bound and lower bounds of the $\alpha$-cut

3. Determine the upper bounds and lower bounds of the productivity score

4. Finally Rank the fuzzy productivity.

\section{EXPERIMENTAL WORK AND DISCUSSION}

This consider takes Indian commercial banks as an illustration, calculates the information collected on the premise of the trapezoidal work to get the upper and lower interim values of each $\alpha$ esteem, and finds the upper and lower bounds of the productivity score utilizing equation (5). We at that point rank the calculated upper and lower bounds of the proficiency score to discover the leading performing banks. This ponders sees banks as intermediation educates and receives the concept of the intermediation approach to recognize yields and inputs. Subsequently, the yields incorporate advance, speculation, and other wage, whereas the inputs comprise of the number of representatives, add up to settled resource, and stores. We treat advance and venture as fuzzy things and analyze the proficiency of the keeping money industry with a trapezoidal work from the fuzzy set hypothesis. The advantage of the trapezoidal work is that uncertain yields still hold the fuzzy characteristics (interim values) when $\alpha=1$. The trigonometric work, another broadly utilized work in fuzzy set hypothesis, relapses into a single esteem when $\alpha=1$ without the fuzzy phenomena.

The furthest left esteem and the furthest right esteem of credit and speculation, characterized by fuzzy wonders, within the trapezoidal function (Fig. 1) must be decided to begin with. In terms of the advance variable, this ponder places the advance variable within the center. Including and subtracting NPLs (loans $\times$ NPLs proportion) which is comes from $a_{3}$ results in $a_{1}$ and $a_{5}$. Including and subtracting one half of NPLs from comes from $a_{3}$ results in $a_{2}$ and $a_{4}$. In terms of the speculation variable, considering that speculation includes benefits and misfortunes from two things, counting buying and offering stocks and bills and long-term venture of equity shares, this ponder places the speculation variable within the center such as $a_{3}$.

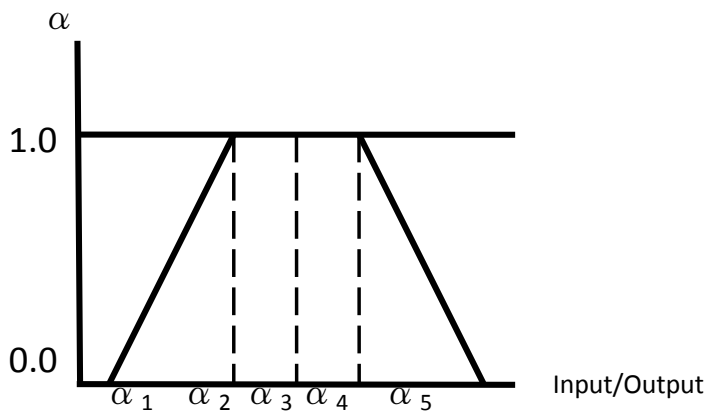

Fig. 1 Trapezoidal Membership Function

After the upper and lower bounds of credit and venture of all test banks are inferred in step 2, we will make utilize of the concept from models (5) and (5) to discover the upper and the lower bounds of the relative proficiency score of each bank. Table 1 appears the conceivable upper and lower bounds of effectiveness scores of each test bank beneath each -cut. The implies the run that the productivity score must drop inside, and implies what the productivity score is most likely to be. The more noteworthy the esteem is, the littler the interim will be between the upper and lower bounds of the productivity score. For illustration, the effectiveness score of Bank 5 (the title of banks and their corresponding series numbers of test banks list in Reference section) isn't less than 0.916 and not more noteworthy at that point 0.969 when , whereas its proficiency score is most likely between 0.929 and 0.956 when . Table 1 too appears that the negligible esteem is 0.479 and the greatest esteem is 1 . There are 14 banks (Bank $1,3,4,7,11,16,20,30$

A bank with the bigger file number is related with a more favored fluffy effectiveness score. Note that the positioning file isn't the Farrell effectiveness (Farrell, 1957). The lists as it were serve to rank DMUs with the fuzzy proficiency scores. Hypothetically, this approach requires the number of $\square$-cuts, $\mathrm{T}$, to be expansive sufficient. In any case, Chen and Klein contended that $\mathrm{T}=3$ or 4 is adequate to separate DMUs.

Table 1: Fuzzy Efficiency Scores of Indian Banks under $\alpha$ value

\begin{tabular}{|c|c|c|c|c|c|c|}
\hline $\begin{array}{c}\text { Sample } \\
\text { Banks }\end{array}$ & $\alpha=0.0$ & $\alpha=0.2$ & $\alpha=0.4$ & $\alpha=0.6$ & $\alpha=0.8$ & $\alpha=1.0$ \\
\hline 1 & $(1,1)$ & $(1,1)$ & $(1,1)$ & $(1,1)$ & $(1,1)$ & $(1,1)$ \\
\hline 2 & $(0.488,0.503)$ & $(0.496,0.681)$ & $(0.405,0.580)$ & $(0.413,0.659)$ & $(0.522,0.657)$ & $(0.632,0.746)$ \\
\hline 3 & $(1,1)$ & $(1,1)$ & $(1,1)$ & $(1,1)$ & $(1,1)$ & $(1,1)$ \\
\hline 4 & $(1,1)$ & $(1,1)$ & $(1,1)$ & $(1,1)$ & $(1,1)$ & $(1,1)$ \\
\hline 5 & $(0.717,0.859)$ & $(0.828,0.766)$ & $(0.721,0.854)$ & $(0.834,0.761)$ & $(0.826,0.748)$ & $(0.829,0.756)$ \\
\hline 6 & $(0.832,0.945)$ & $(0.846,0.955)$ & $(0.860,0.921)$ & $(0.874,0.988)$ & $(0.888,0.924)$ & $(0.945,0.924)$ \\
\hline 7 & $(1,1)$ & $(1,1)$ & $(1,1)$ & $(1,1)$ & $(1,1)$ & $(1,1)$ \\
\hline 8 & $(0.770,0.822)$ & $(0.780,0.855$ & $(0.790,0.832)$ & $(0.800,0.811)$ & $(0.811,0.724)$ & $(0.821,0.715)$ \\
\hline 9 & $(0.828,1)$ & $(0.838,1)$ & $(0.848,1)$ & $(0.858,1)$ & $(0.868,1)$ & $(0.878,1)$ \\
\hline
\end{tabular}




\begin{tabular}{|c|c|c|c|c|c|c|}
\hline 10 & $(0.752,1)$ & $(0.765,1)$ & $(0.778,1)$ & $(0.811,1)$ & $(0.825,1)$ & $(0.833,0.975)$ \\
\hline 11 & $(1,1)$ & $(1,1)$ & $(1,1)$ & $(1,1)$ & $(1,1)$ & $(1,1)$ \\
\hline 12 & $(0.686,0.755)$ & $(0.691,0.754)$ & $(0.697,0.753)$ & $(0.702,0.752)$ & $(0.708,0.751)$ & $(0.714,0.750)$ \\
\hline 13 & $(0.535,0.668)$ & $(0.542,0.662)$ & $(0.549,0.656)$ & $(0.555,0.650)$ & $(0.562,0.644)$ & $(0.569,0.638)$ \\
\hline 14 & $(0.704,0.761)$ & $(0.707,0.758)$ & $(0.710,0.755)$ & $(0.712,0.752)$ & $(0.715,0.749)$ & $(0.718,0.746)$ \\
\hline 15 & $(0.576,0.643)$ & $(0.583,0.734)$ & $(0.541,0.426)$ & $(0.600,0.718)$ & $(0.710,0.710)$ & $(0.619,0.702)$ \\
\hline 16 & $(1,1)$ & $(1,1)$ & $(1,1)$ & $(1,1)$ & $(1,1)$ & $(1,1)$ \\
\hline 17 & $(0.812,0.922)$ & $(0.828,0.933)$ & $(0.955,0.989)$ & $(0.861,0.932)$ & $(0.878,0.945)$ & $(0.895,0.954)$ \\
\hline 18 & $(0.870,0.998)$ & $(0.846,0.998)$ & $(0.792,0.892)$ & $(0.798,0.885)$ & $(0.804,0.879)$ & $(0.810,0.873)$ \\
\hline 19 & $(0.882,0.956)$ & $(0.888,0.942)$ & $(0.894,0.988)$ & $(0.888,0.980)$ & $(0.900,0.945)$ & $(0.889,0.988)$ \\
\hline 20 & $(1,1)$ & $(1,1)$ & $(1,1)$ & $(1,1)$ & $(1,1)$ & $(1,1)$ \\
\hline 21 & $(0.645,0.707)$ & $(0.649,0.705)$ & $(0.653,0.703)$ & $(0.657,0.701)$ & $(0.661,0.788)$ & $(0.665,0.696)$ \\
\hline 22 & $(0.532,0.644)$ & $(0.537,0.638)$ & $(0.543,0.632)$ & $(0.549,0.627)$ & $(0.554,0.621)$ & $(0.560,0.616)$ \\
\hline 23 & $(0.516,0.735)$ & $(0.522,0.721)$ & $(0.527,0.709)$ & $(0.534,0.796)$ & $(0.542,0.745)$ & $(0.550,0.672)$ \\
\hline 24 & $(0.579,0.945)$ & $(0.583,0.922)$ & $(0.591,0.955)$ & $(0.512,0.911)$ & $(0.450,0.962)$ & $(0.493,0.941)$ \\
\hline 25 & $(0.786,0.865)$ & $(0.790,0.861)$ & $(0.794,0.858)$ & $(0.798,0.854)$ & $(0.803,0.850)$ & $(0.807,0.846)$ \\
\hline 26 & $(0.852,0.900)$ & $(0.854,0.921)$ & $(0.856,0.945)$ & $(0.858,0.923)$ & $(0.860,0.956)$ & $(0.862,0.943)$ \\
\hline 27 & $(0.686,0.821)$ & $(0.693,0.814)$ & $(0.700,0.808)$ & $(0.707,0.801)$ & $(0.714,0.795)$ & $(0.720,0.788)$ \\
\hline 28 & $(0.552,0.634)$ & $(0.556,0.630)$ & $(0.560,0.625)$ & $(0.564,0.621)$ & $(0.568,0.616)$ & $(0.572,0.612)$ \\
\hline 29 & $(0.714,0.858)$ & $(0.721,0.851)$ & $(0.728,0.844)$ & $(0.736,0.837)$ & $(0.744,0.830)$ & $(0.751,0.823)$ \\
\hline 30 & $(1,1)$ & $(1,1)$ & $(1,1)$ & $(1,1)$ & $(1,1)$ & $(1,1)$ \\
\hline
\end{tabular}

Table 2 appears that there are 14 effective banks (with a positioning file of 1), which are comparing to those banks with the upper and lower bounds of an productivity score of 1 in Table 1. Other banks are wasteful (with a positioning list to be less than 1), which are those banks with at slightest one lower bound of less than 1; for case, the positioning list is 0.989 for Bank 19, which has the upper and lower bounds of an proficiency score of 1 when $\alpha \leq 0.4$.

Table 2 Ranking of Fuzzy Efficiency Score of Indian Banks

\begin{tabular}{|c|c|c|}
\hline Ranking & Sample Bank & Ranking Index \\
\hline 1 & 1 & 1.000 \\
\hline 1 & 3 & 1.000 \\
\hline 1 & 4 & 1.000 \\
\hline 1 & 7 & 1.000 \\
\hline 1 & 11 & 1.000 \\
\hline 1 & 16 & 1.000 \\
\hline 1 & 20 & 0.889 \\
\hline 1 & 30 & 0.840 \\
\hline 15 & 19 & 0.824 \\
\hline 17 & 6 & 0.818 \\
\hline 18 & 26 & 0.817 \\
\hline 19 & 17 & 0.762 \\
\hline 20 & 9 & 0.733 \\
\hline 23 & 5 & \\
\hline 24 & 8 & \\
\hline
\end{tabular}




\begin{tabular}{|c|c|c|}
\hline 25 & 18 & 0.729 \\
\hline 26 & 25 & 0.721 \\
\hline 27 & 38 & 0.674 \\
\hline 28 & 29 & 0.633 \\
\hline 29 & 37 & 0.628 \\
\hline 30 & 10 & 0.617 \\
\hline
\end{tabular}

Experimental comes about appear that there are 14 banks (Bank 1, 3, 4, 7, 11, 16, 20, 30) with the upper and lower bounds of an effectiveness score of 1 ; in other words, they are productive banks without a doubt. These banks, of course, are too effective beneath the customary fresh DEA show. In any case, there are another 5 banks, Bank 6, 9, 17, and 19 that are productive (with effectiveness score 1) beneath non-fuzzy condition, whereas their positioning lists are less than 1 with rankings between 15 and 20 (i.e., at slightest one lower bound is less than 1) beneath fuzzy condition. This may demonstrate that the FDEA approach might have a better capacity to segregate between productive and wasteful banks than the routine DEA approach.

There are a few conceivable expansions for this think about. We are able apply this approach to analyze other budgetary teach, such as foreign-owned banks and credit unions. Besides, this strategy can offer assistance us to explore money related teach with lost and/or deficient information.

\section{REFERENCES}

[1] Sherman, H.D., Gold, F., 1985. Bank branch operating efficiency: Evaluation with data envelopment analysis. Journal of Banking and Finance, 9, 297-316.

[2] Aly, H.Y., Grabowski, R., Pasurka, C., Rangan, N., 1990. Technical, scale and allocative efficiencies in U.S. banking: An empirical investigation. The Review of Economics and Statistics, 72, 211-218.

[3] Yue, P., 1992. Data envelopment analysis and commercial bank performance: A primer with applications to Missouri banks. Federal Reserve Bank of St. Louis, 31-45.

[4] Miller, S.M., Noulas, A.G., 1996. The technical efficiency of large bank production. Journal of Banking and Finance, 20, 495-509.

[5] Berger, A.N., DeYoung, R., 1997. Problem loans and cost efficiency in commercial banks. Journal of Banking and Finance, 21, 849-870.

[6] Berger, A.N., Humphrey, D.B., 1997. Efficiency of financial institutions: International survey and directions for future research. Journal of Operational Research, 98, 175-212.

[7] Kao, C., Liu, S.T., 2000a. Fuzzy efficiency measures in data envelopment analysis. Fuzzy Sets and Systems, 113, 427-437.

[8] Kao, C., Liu, S.T., 2000b. Data envelopment analysis with missing data: An application to University libraries in Taiwan. Journal of the Operational Research Society, 51, 897-905.

[9] Cooper, W.W., Park, K.S., Yu, G., 1999. IDEA and ARIDEA: Models for dealing with imprecise data in DEA.
Management Science, 45, 597-607.

[10] Li, Y., 2003. The Asian financial crisis and nonperforming loans: Evidences from commercial banks in Taiwan. International Journal of Management, 20, 69-74.

[11] Hoshi, T., Kashyap, A., 1999. The Japanese banking crisis: Where did it come from and how will it end? NEBR Working Paper, 7250.

[12] Park, J.H., 2002. Globalization of financial markets and the Asian crisis: Some lessons for third world developing countries. Journal of Third World Studies, 19, 141-164.

[13] Kao, C., Liu, S.T., 2004. Predicting bank performance with financial forecasts: A case of Taiwan commercial banks. Journal of Banking and Finance, 28, 2353-2368.

[14] Zadeh, L. A., 1978. Fuzzy sets as a basis for a theory of possibility. Fuzzy Sets and Systems, 1, 3-28.

[15] Saati, S.M., Memariani A., Jahanshahloo G.R., 2002. Efficiency analysis and ranking of DMUs with fuzzy data. Fuzzy Optimization and Decision Making, 3, 255267.

[16] Entani, T., Maeda, Y., Tanaka, H., 2002. Dual models of interval DEA and its extension to interval data. European Journal of Operational Research, 136, 32-45.

[17] Lertworasirikul S., Fang S.C., Nuttle H.L.W., Joines J.A., 2003. Fuzzy BCC model for data envelopment analysis. Fuzzy Optimization and Decision Making, 2, 337-358.

[18] Lertworasirikul S., Fang S.C., Joines J.A., Nuttle H.L.W., 2003. Fuzzy data development analysis (DEA): A possibility approach. Fuzzy Sets and Systems, 139, 379394

[19] Chen, S.H., 1985. Ranking fuzzy numbers with maximizing set and minimizing set. Fuzzy Sets and Systems, 17, 113-129.

[20] Tseng, T.Y., Klein, C.M., 1989. New algorithm for the ranking procedure in fuzzy decision making. IEEE Transactions on Systems, Man and Cybernetics, 19, 1289-1296.

[21] Chen, C.B., Klein, C.M., 1997. A simple approach to ranking a group of aggregated fuzzy utilities. IEEE Transactions on Systems, Man and Cybernetics Part, 27, 26-35.

[22] Kao, C., Liu, S.T., 2003, A mathematical programming approach to fuzzy efficiency ranking. International Journal of Production Economics, 86, 145-154.

[23] Chen, C.B., Klein, C.M., 1997. A simple approach to ranking a group of aggregated fuzzy utilities. IEEE Transactions on Systems, Man and Cybernetics Part, 27, 26-35. 